\title{
Commentary: Inflammation, hemocompatibility, and allosensitization-What is next?
}

Federico Pappalardo, MD, ${ }^{\mathrm{a}, \mathrm{b}}$ Andrea Montisci, MD, ${ }^{\mathrm{c}, \mathrm{d}}$ and Antonio Miceli, MD, $\mathrm{PhD}^{\mathrm{e}}$

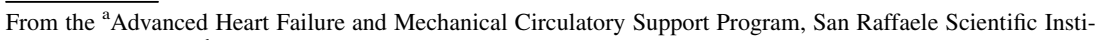
tute, Milan, Italy; ${ }^{b}$ Vita-Salute San Raffaele University, Milan, Italy; ${ }^{\mathrm{c}}$ Department of Anesthesia and Intensive Care, Cardiothoracic Center, Istituto Clinico Sant'Ambrogio, Gruppo Ospedaliero San Donato, University and Research Hospitals, Milan, Italy; ${ }^{\mathrm{d} D e p a r t m e n t}$ of Cardiac Surgery, University of Milan, Milan, Italy; and ${ }^{\mathrm{e}}$ Department of Minimally Invasive Cardiac Surgery, Cardiothoracic Center, Istituto Clinico Sant'Ambrogio, Gruppo Ospedaliero San Donato, Milan, Italy.

Disclosures: Authors have nothing to disclose with regard to commercial support.

Received for publication April 21, 2019; accepted for publication April 22, 2019; available ahead of print June 12, 2019 .

Address for reprints: Antonio Miceli, MD, PhD, Department of Minimally Invasive Cardiac Surgery, Cardiothoracic Center, Istituto Clinico Sant'Ambrogio, Gruppo Ospedaliero San Donato, Via Giuseppe Faravelli 16, 20149 Milan, Italy (E-mail: antoniomiceli79@alice.it).

J Thorac Cardiovasc Surg 2020;159:164-5

0022-5223/\$36.00

Copyright (c) 2019 by The American Association for Thoracic Surgery

https://doi.org/10.1016/j.jtcvs.2019.04.065
}

Outcomes of patients treated with left ventricular assist devices (LVADs) have continuously improved in recent years, reaching a similar survival to that of patients undergoing heart transplantation (HTx). ${ }^{1}$ As result, LVADs have become an effective therapy for the growing number of patients suffering from end-stage heart failure in the era of reduced organ availability.

Previous studies reported that LVADs (mostly first- and second-generation devices) implanted as bridge to transplant or bridge to candidacy strategy are variably associated with allosensitization, which increases the time spent on the waiting list as well as the risk of antibodymediated reactions after HTx. ${ }^{2}$ In this issue of the Journal, Iyengar and colleagues ${ }^{3}$ report their investigation of immunologic responses of patients receiving mechanical supports, adding evidence of how inflammation may play an important role in the pathogenesis of allosensitization. Specifically, in a small cohort of patients receiving the HeartMate II (Abbott Laboratories, Abbott Park, Ill), Iyengar and colleagues ${ }^{3}$ found that (1) no patients had development of de novo HLA antibodies after device implantation, and (2) there was a remarkable increase in inflammatory cytokines after the implantation, which drove the maturation of B cell phenotypes and pointed out the role of inflammatory milieu in driving allosensitization guided by already existing sensitized B cells.

These findings arise a wider horizon of discussion, which goes beyond allosensitization. An important question is the timing of HTx after LVAD implantation. Recent studies have shown that HTx performed less than 3 months after LVAD implantation is associated with worse outcomes, ${ }^{4}$ whereas graft survival is significantly longer in those patients who have a decline of panel reactive antibodies activity. ${ }^{5}$ On this basis, we hypothesize that HTx should

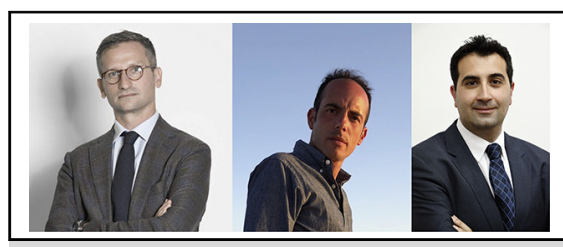

Left to right. Federico Pappalardo, MD, Andrea Montisci, MD, and Antonio Miceli, MD, PhD

\section{Central Message}

Inflammation, hemocompatibility, and allosensitization are the new key factors to improving left ventricular assist device outcomes.

See Article page 155 .

be performed when cytokine storm induced by LVAD implantation has declined, providing the absence of life-threatening, device-related, complications.

Iyengar and colleagues ${ }^{3}$ showed a great increase in cytokines after LVAD implantation, with an early peak of monocyte chemoattractant protein and interleukins 6,8 , and10, which are responsible of inflammatory response, and a late peak of vascular endothelial growth factor, fibroblast growth factors, epidermal growth factor, and interleukins 3, 4, and 5, associated with angiogenesis and fibroblast proliferation. This finding underlines the significance of cross talk between inflammation and coagulation, which can be defined as the presence of common biochemical pathways simultaneously determining inflammatory reaction and coagulative system activation. ${ }^{6}$

Among many mechanisms sustaining this multifactorial process, the hemocompatibility (ie, the nature and effects of interaction between biomaterials and blood ${ }^{7}$ ) of LVADs plays an essential role, in terms either of genesis of thromboembolic complications or of shear stress-induced inflammation. Improvement in hemocompatibility therefore not only would lead to less thromboembolic complications but also might possibly reduce initiation and maintenance of an inflammatory state. In this regard, the improved hemocompatibility of third-generation LVAD (HeartMate 3; Abbott Laboratories) should offer a possible solution to this vicious circle. The analysis of the hemocompatibility-related events in the MOMENTUM trial showed a greater freedom from HRAEs of HeartMate 3 in comparison with the HeartMate II LVAD at 6 months. ${ }^{8}$ 
In conclusion, Iyengar and colleagues ${ }^{3}$ have opened a discussion on the importance of the relationship among inflammation, hemocompatibility and allosensitization that will appear on the top of the research agenda in the next years.

\section{References}

1. Kormos RL, Cowger J, Pagani FD, Teuteberg JJ, Goldstein DJ, Jacobs JP, et al. The Society of Thoracic surgeons intermacs database annual report: evolving indications, outcomes, and scientific partnerships. Ann Thorac Surg. 2019;107:341-53.

2. Kaczmarek I, Deutsch MA, Kauke T, Beiras-Fernandez A, Schmoeckel M, Vicol C, et al. Donor-specific HLA alloantibodies: long-term impact on cardiac allograft vasculopathy and mortality after heart transplant. Exp Clin Transplant. 2008:6:229-35.
3. Iyengar A, Wisniewski N, Kwon OJ, Cadeiras M, Deng M, Schaenman J, et al. Temporal expression of cytokines and B-cell phenotypes during mechanical circulatory support. J Thorac Cardiovasc Surg. 2020;159:155-63.

4. Steffen RJ, Blackstone EH, Smedira NG, Soltesz EG, Hoercher KJ, Thuita L, et al. Optimal timing of heart transplant after HeartMate II left ventricular assist device implantation. Ann Thorac Surg. 2017;104:1569-76.

5. Schaffer JM, Singh SK, Reitz BA, Oyer PE, Robbins RC, Mallidi HR. Heart transplant graft survival is improved after a reduction in panel reactive antibody activity. J Thorac Cardiovasc Surg. 2013;145:555-64; discussion 564-5.

6. Foley JH, Conway EM. Cross talk pathways between coagulation and inflammation. Circ Res. 2016;118:1392-408.

7. Weber M, Steinle H, Golombek S, Hann L, Schlensak C, Wendel HP, et al. Bloodcontacting biomaterials: in vitro evaluation of the hemocompatibility. Front Bioeng Biotechnol. 2018;6:99.

8. Uriel N, Colombo PC, Cleveland JC, Long JW, Salerno C, Goldstein DJ, et al. Hemocompatibility-related outcomes in the MOMENTUM 3 trial at 6 months: a randomized controlled study of a fully magnetically levitated pump in advanced heart failure. Circulation. 2017;135:2003-12. 